\title{
Double Cystic Duct Not Detected by Imaging But Diagnosed on Intraoperative Dissection in Laparoscopic Cholecystectomy: A Case Report, Hatwan Hospital-Sulaimani Province-Kurdistan-Iraq
}

\author{
Hiwa O. Ahmed', Amir Murad Khodadad² \\ ${ }^{1}$ Faculty of Medical Sciences, School of Medicine, Founder and Manager of Hatwan Hospital, University of Sulaimani, Kurdistan \\ Region Sulaimani City, Iraq \\ ${ }^{2}$ Faculty of Medical Sciences, School of Medicine, University of Sulaimani, Kurdistan Region Sulaimani City, Iraq \\ Email: hatwan@gmail.com
}

How to cite this paper: Ahmed, H.O. and Khodadad, A.M. (2017) Double Cystic Duct Not Detected by Imaging But Diagnosed on Intraoperative Dissection in Laparoscopic Cholecystectomy: A Case Report, Hatwan Hospital-Sulaimani Province-Kurdistan-Iraq. Case Reports in Clinical Medicine, 6, 89-93. https://doi.org/10.4236/crcm.2017.63008

Received: December 8, 2016

Accepted: March 28, 2017

Published: March 31, 2017

Copyright $\odot 2017$ by authors and Scientific Research Publishing Inc. This work is licensed under the Creative Commons Attribution International License (CC BY 4.0).

http://creativecommons.org/licenses/by/4.0/

\section{Open Access}

\begin{abstract}
The incidence rate of bile duct injury during laparoscopic cholecystectomy has not been changed for many years. This may be because of biliary tree abnormalities, as variation in cystic duct anatomy is quite common. One of the extremely rare anomalies is a double cystic duct. An old lady underwent laparoscopic cholecystectomy for symptomatic gallstones. Without any clue for this anomaly in preoperative checkup, we found two cystic ducts during the laparoscopy. Operation completed laparoscopically, with smooth early and later postoperative checkups till now.
\end{abstract}

\section{Keywords}

Double Cystic Duct, Intraoperative Diagnosis, Bile Tree Injury

\section{Introduction}

Laparoscopic cholecystectomy is now a gold standard treatment modality for symptomatic gallstone diseases. However, the incidence rate of bile duct injury has not been changed for many years [1]. This may be because of biliary tree abnormalities, as variation in cystic duct anatomy is quite common, which may be detected by preoperative ultrasonography, magnetic resonant cholangiopancreatography [2] [3].

However, a double cystic duct is extremely rare; only 9 cases have been re- 
ported in the literature with preoperative suspension or diagnosis of double cystic duct that was confirmed intraoperatively [4]. But there is only one report of double cystic duct in the literature, by (Mittelstaedt $C A$ ) that was found in laparoscopic cholecystectomy without diagnosis in preoperative preparation [2] [5].

\section{Case Report}

A 58-year-old lady (Table 1) with symptomatic gallstones prepared for laparoscopic cholecystectomy, in the history had features of cholangitis and previous attacks of biliary colic.

Preoperative ultrasonography and MRCP were done to exclude CBD stones. Ultrasonography and MRCP showed normal gall bladder wall thickness and normal CBD and multiple small gallstones. Presence of double cystic ducts were confirmed by intraoperative suspension, meticulous dissection, and exploration of the cystohepatic (Calot's) triangle, detailed in Table 2.

Formal four-port laparoscopy was started. After the initial dissection, the cystic duct was clipped and divided. Further dissection of the infundibulum revealed a tubular structure extending from the neck of the gallbladder to the common hepatic duct that was one centimeter above the insertion of cystic duct. It was not pulsating to be the Caterpillar hump of right hepatic artery.

Further dissection of the distal part of this tubular structure was connected to the infundibulum of the gallbladder. The tubular structure did not run over the surface of the gallbladder instead it ended in the infundibulum. After the exploration of the proximal side of the tubular structure, it ended like an ordinary cystic duct in the common duct one centimeter above the joining point of the cystic duct to the common duct as shown in Picture 1. The tubular structure

Table 1. Showing demographic data of the patient.

\begin{tabular}{cc}
\hline Demographic data & The patients details \\
\hline Age & 58 years old \\
Gender & Female \\
Marital status & Married \\
Off springs & 5 children: 3 sons and two daughters \\
Occupation & Housewife \\
Residency & Rural area (Qaladuze-Sulaimani Governorate-Kurdistan-Iraq) \\
\hline
\end{tabular}

Table 2. Showing preoperative finding in imaging of the patient.

\begin{tabular}{ccc}
\hline Finding & Ultrasonography & MRCP \\
\hline $\begin{array}{c}\text { Gallstones } \\
\text { Wall thickness of } \\
\text { gallbladder }\end{array}$ & + & + \\
CBD & $\begin{array}{c}\text { Normal } \\
\text { and no stones }\end{array}$ & $\begin{array}{c}\text { Normal diameter and no stones no narrowing. } \\
\text { free passage of contrast to duodenum }\end{array}$ \\
Bile tree anomalies & - & - \\
\hline
\end{tabular}


was then clipped and divided. The artery was then visible which was clipped and transected. The gallbladder was then removed.

Hand drawing of the gall bladder and double cystic ducts shown in Diagram 1.

Macroscopic examination of the extracted gall bladder revealed double cystic ducts and this was confirmed by probing of their lumens.

The patient had an uneventful early postoperative period, and was discharged on the first postoperative day in good general condition.

The patient's first visit was after 7 days and on further follow-up, there were no features of complications with liver function tests being normal. The patient followed till now, she is in her $12^{\text {th }}$ post-operative month having no features of complications with normal liver function tests and ultrasonography checkup.

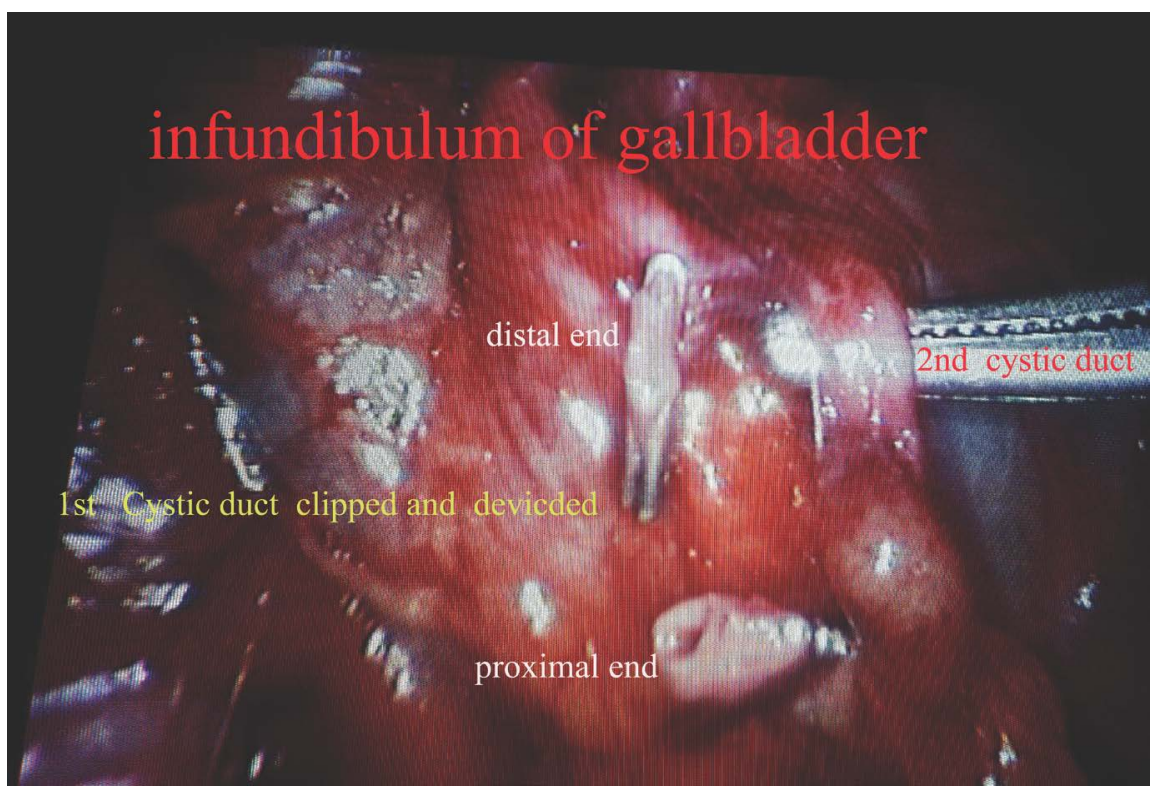

Picture 1. Detail of the exploration of first and second cystic duct.

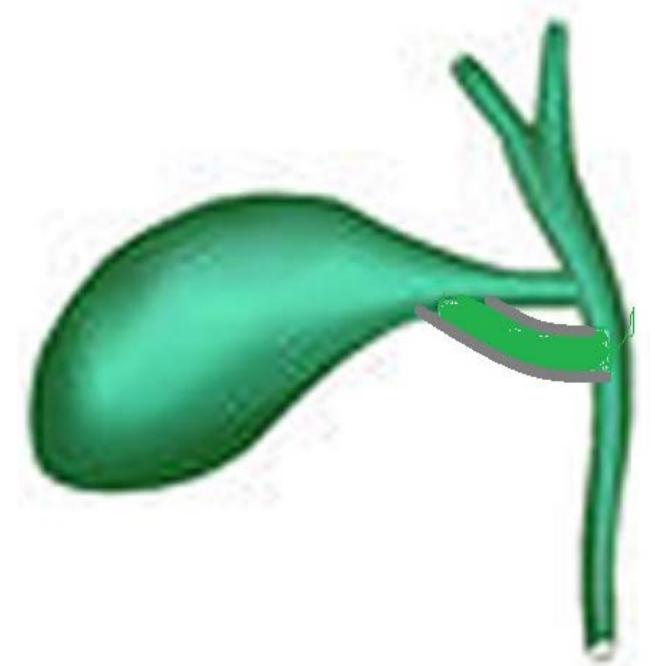

Diagram 1. Showing position of the cystic ducts. 


\section{Discussion}

Although imagings are of little help in diagnosis of double cystic duct, endoscopic retrograde cholangiopancreatography may suspect and be confirmed by intraoperative cholangiography [6] [7].

The small caliber of the cystic duct and its tortuosity make detection difficult with axial CT and US and cholescintigraphy is further limited by low resolution. Optimal visualization of the cystic duct requires direct cholangiography or MR cholangiopancreatography, both of which depict the cystic duct in the coronal plane along its long axis [3] [6] [8].

Color Doppler US may be used to distinguish bile ducts from the vessels [9]. Double cystic duct is extremely rare and poses a challenge for surgeons during an operation. Diagnosis of this condition is usually confirmed during laparoscopic cholecystectomy. This is the second report of double cystic duct found in laparoscopic cholecystectomy without even suspicion in preoperative preparation, the first case reported by Mittelstaedt CA [2].

In practice of laparoscopic cholecystectomy, this abnormality which is extremely rare may be present without any suspension before surgery. The anticipation of the probable existence of such bile duct variation serves as the most important factor in preventing iatrogenic bile duct injuries [10]. Awareness among the surgeons regarding this anatomic anomaly could help in avoiding converted laparotomy and reduce the risk of complications.

\section{Conclusion}

In practice of laparoscopic cholecystectomy, this abnormality may be present without any suspension before surgery. Awareness of probable existence of double cystic duct may save us, in injury to bile tree and unnecessary conversion to open cholecystectomy.

\section{References}

[1] Kwangsik, C. (2014) Recent Classifications of the Common Bile Duct Injury. Korean J Hepatobiliary Pancreat Surg., 18, 69-72. https://doi.org/10.14701/kjhbps.2014.18.3.69

[2] Turner, M.A. and Fulcher, A.S. (2001) The Cystic Duct: Normal Anatomy and Disease Processes. Radiographics Journal, 21, 3-22.

[3] Huston, T.L. and Dakin, G.F. (2008) Double Cystic Duct. Canadian Journal of Surg., 51, E9-E10.

[4] Khadijeh, A., et al. (2014) Double Cystic Duct. International Journal of Anatomy and Research, 2, 601-604.

[5] Tsutsumi, S., Hosouchi, Y., Shimura, T., et al. (2000) Double Cystic Duct Detected by Endoscopic Retrograde Cholangiopancreatography and Confirmed by Intraoperative Cholangiography in Laparoscopic Cholecystectomy: A Case Report. Hepatogastroenterology, 47, 1266-1268.

[6] Hirono, Y., Takita, Y., Nitta, N., et al. (1997) Double Cystic Duct Found by Intraoperative Cholangiography in Laparoscopic Cholecystectomy. Surgical Laparoscopy \& Endoscopy, 7, 263-265. https://doi.org/10.1097/00019509-199706000-00019 
[7] Shivhare, R. and Sikora, S.S. (2004) Double Cystic Duct: A Rare Biliary Anomaly Encountered at Laparoscopic Cholecystectomy. Journal of Laparoendoscopic \& Advanced Surgical Techniques, 12, 391-392.

https://doi.org/10.1089/109264202320884162

[8] Nakasugi, H., Kobayashi, S. and Sakamoto, K. (1995) A Case of Double Cystic Duct with Cholecystolithiasis Treated by Laparoscopy. Journal of Hepato-Biliary-Pancreatic Surgery, 2, 68-71. https://doi.org/10.1007/BF02348291

[9] Aristotle, S. and Christilda, F. (2011) A Duplication of the Cystic Duct-Case Report. European Journal of Anesthesia, 15, 176-178.

[10] Shabanali, A., Reza, D.M., Khadijeh, A., et al. (2014) Double Cystic Duct. International Journal of Anatomy and Research, 2, 601-604.

Submit or recommend next manuscript to SCIRP and we will provide best service for you:

Accepting pre-submission inquiries through Email, Facebook, LinkedIn, Twitter, etc. A wide selection of journals (inclusive of 9 subjects, more than 200 journals)

Providing 24-hour high-quality service

User-friendly online submission system

Fair and swift peer-review system

Efficient typesetting and proofreading procedure

Display of the result of downloads and visits, as well as the number of cited articles Maximum dissemination of your research work

Submit your manuscript at: http://papersubmission.scirp.org/

Or contact crcm@scirp.org 